\title{
Bônus demográfico no Brasil: do nascimento tardio à morte precoce pela Covid-19
}

\author{
José Eustáquio Diniz Alves*
}

\section{Introdução}

A discussão sobre população e desenvolvimento é tão antiga quanto o debate iluminista sobre o progresso e as consequências da Revolução Industrial. De maneira bem resumida, podemos dizer que há três posições que se confrontam ao longo dos últimos 250 anos: a primeira está expressa nas obras de Adam Smith (1723-1790), Marquês de Condorcet (1743-1794) e William Godwin (1756-1836), que consideravam de maneira positiva a contribuição do crescimento populacional para o desenvolvimento econômico (pelo menos até o surgimento do Estado Estacionário, como mostrou John Stuart Mill, em 1848); a segunda posição foi expressa por Thomas Malthus (1766-1834), que não acreditava no desenvolvimento econômico e ainda defendia a ideia de que qualquer melhoria das condições de vida da população seria impossível em decorrência da tendência de um inevitável crescimento populacional descontrolado; e a terceira é aquela defendida por Karl Marx de que a população é neutra, pois o que determina o desenvolvimento das forças produtivas é o processo de acumulação de capital, que, ao se reproduzir, produz uma superpopulação relativa capaz de garantir a manutenção da taxa de lucro (ALVES, 2006).

Dessa forma, o debate demográfico sobre população e desenvolvimento tem sido, ao longo do tempo, profundamente marcado e até contaminado por estas três posições, que, em síntese, são: o crescimento populacional é positivo; o crescimento populacional é negativo; e o crescimento populacional é neutro. 0 conceito de bônus demográfico, até certo ponto, veio modificar todo este debate anterior, pois, em vez de focar nas taxas de crescimento da população, passou a enfatizar o papel determinante das relações intergeracionais sobre o processo de desenvolvimento.

\footnotetext{
*Pesquisador aposentado, Rio de Janeiro-RJ, Brasil (jed_alves@yahoo.com.br; http://orcid.org/0000-0001-6095-9668).
} 
O bônus demográfico é um filho legítimo da transição demográfica, já que a redução das taxas brutas de natalidade e mortalidade gera, deterministicamente, uma mudança na estrutura etária da população. A transição demográfica engendra, necessariamente, uma mudança na razão de dependência, pois diminui o tamanho proporcional dos grupos etários mais jovens e aumenta o dos grupos etários em idade economicamente ativa. Assim, o bônus demográfico é uma janela de oportunidade que ocorre quando há uma redução da razão de dependência demográfica, que é o coeficiente entre o segmento etário da população definido como economicamente dependente (os menores de 15 anos de idade e os maiores de 65 anos) e o segmento etário potencialmente produtivo (15 a 64 anos).

Apresentado dessa forma, parece que o bônus demográfico é uma definição científica de fácil entendimento e aceitação imediata e universal. Contudo, não tem sido de aceitação imediata e automática. Como veremos a seguir, o conceito de bônus demográfico nunca conseguiu superar ou neutralizar os preconceitos ideológicos alimentados durante décadas. Ele demorou a entrar no centro do debate da demografia brasileira, chegou com muito atraso ao conhecimento dos formuladores de políticas públicas no Brasil e não existe consenso sobre como e quando acontecerá o seu fim.

Assim, vamos fazer uma breve resenha sobre as origens do conceito de bônus demográfico e tentar reconstruir a conjuntura que permitiu sua aceitação no Brasil, os mecanismos que possibilitaram sua difusão na sociedade brasileira e o debate sobre o seu término, numa conjuntura que já era complicada em decorrência do fraco dinamismo do mercado de trabalho e que se tornou, irremediavelmente, desfavorável com o surgimento da pandemia da Covid-19.

\section{Breve resenha sobre o surgimento do conceito de bônus demográfico}

O marco inicial da discussão sobre a importância da estrutura etária da população para o desenvolvimento está no famoso livro População e desenvolvimento econômico, de Coale e Hoover (1966), publicado originalmente em 1958. Todavia, como a idade mediana da população mundial estava abaixo de 23 anos na década de 1950, o livro dos pesquisadores da Universidade de Princeton buscou evidenciar o ônus de uma estrutura etária muito jovem, em vez de mostrar as oportunidades de uma estrutura etária com alta proporção de pessoas em idade ativa.

Todavia, com a generalização da queda da fecundidade em grande parte do mundo, as vantagens da redução da base da pirâmide populacional foram ficando mais evidentes. Embora não tenham usado o termo bônus (ou dividendo) demográfico, Cutler et al. (1990), analisando o processo de envelhecimento populacional, não deixam dúvidas sobre as vantagens da mudança da estrutura etária: "Nossa conclusão é que a queda da fecundidade representa uma oportunidade e não um problema" (CUTLER et al., 1990, p. 3). Relatório do Banco Mundial também mostrou as vantagens de uma rápida transição demográfica 
para a aceleração do desenvolvimento econômico nos países do leste asiático (WORLD BANK, 1993).

Mas, apesar das crescentes evidências de que uma rápida queda do número médio de filhos propiciaria uma estrutura etária favorável à decolagem do desenvolvimento econômico e social, esta questão não fez parte do Programa de Ação da Conferência Internacional de População e Desenvolvimento (CIPD) do Cairo, em 1994. Ou seja, o importante conceito de bônus demográfico não foi discutido e incorporado no relatório final da maior Conferência sobre População e Desenvolvimento, ocorrida na última década do século XX. A CIPD do Cairo não analisou e nem propôs políticas adequadas para o aproveitamento da janela de oportunidade surgida com a redução da razão de dependência demográfica.

Não obstante, o sucesso da transição demográfica dos países do leste asiático e a manutenção de altas taxas de crescimento econômico e social, com redução da pobreza, chamaram a atenção dos pesquisadores de todo o mundo. No texto "Demographic transitions and economic miracles in emerging Asia”, Bloom e Williamson (1998) introduzem variáveis populacionais em um modelo empírico de crescimento econômico, demonstrando que a transição demográfica contribuiu substancialmente para o sucesso asiático: "0 milagre ocorreu em parte porque a transição demográfica do Leste Asiático resultou em uma população em idade ativa crescendo a uma taxa muito mais rápida do que à da população dependente" (BLOOM; WILLIAMSON, 1998, p. 419).

Outro passo importante na consolidação da formulação do conceito de bônus (dividendo) demográfico foi dado no artigo de Lee, Mason e Miller (2000), em que os autores, usando dados de pesquisas domiciliares de Taiwan sobre rendimento, poupança, fecundidade e mortalidade, simulam as principais motivações que estão por trás da acumulação de ativos (financeiros e não financeiros) nas diversas etapas do ciclo de vida por parte das unidades familiares. Eles concluem mostrando que a redução da fecundidade e o prolongamento da esperança de vida contribuem para o aumento das taxas agregadas de riqueza e poupança, em decorrência das mudanças na estrutura etária e da baixa razão de dependência.

Por último, mas não menos importante, foi a publicação, em 2001, do livro Population matters, de Birdsall, Kelley e Sinding, obra que reúne uma série de artigos de pesquisadores renomados sobre o tema e consolida a noção de que a população importa e que uma estrutura etária favorável, decorrente da transição demográfica, é um fator essencial para a decolagem do desenvolvimento e para se conseguir um padrão mais elevado de bem-estar para toda a população.

\section{A difusão do conceito do bônus demográfico na Abep e na sociedade brasileira}

A discussão sobre a mudança da estrutura etária no Brasil é contemporânea ao debate sobre a queda da fecundidade. Um dos textos relevantes para a análise das alterações no padrão demográfico brasileiro e suas implicações para a agenda social foi produzido por Martine, Carvalho, Arias (1994), embora sem usar o termo bônus ou dividendo demográfico. 
Somente no início dos anos 2000 é que começaram a surgir publicações em que estes termos aparecem (BARROS et al. 2001; ALVES, 2002).

Naquela época, o posicionamento mais significativo sobre as mudanças na estrutura etária brasileira ocorreu com o discurso do presidente da IUSSP na abertura da XXIV Conferência Geral de População, em Salvador, em 19 de agosto de 2001, quando ele encerrou sua fala com o seguinte alerta: “Exatamente por ser estreita, em comparação com aquela vivenciada no passado pelo Primeiro Mundo, é que se tem de aproveitar dessa janela da maneira mais eficiente e eficaz possível” (CARVALHO, 2001, p. 12).

Mas no Brasil esta discussão sobre o bônus (dividendo ou janela de oportunidade demográfica) tinha um alcance muito limitado dentro e fora da Associação Brasileira de Estudos Populacionais (Abep). Sem embargo, este quadro começou a mudar a partir de 2005, quando a nova diretoria da Abep, ${ }^{1}$ gestão 2005/06, presidida e estimulada por George Martine, buscou formas de incentivar esta discussão internamente na associação e também incluí-la no debate nacional sobre as questões demográficas brasileiras, por meio de maior presença na mídia.

Um marco deste novo momento foi o número especial da Rebep (v. 22, n. 2, jul./dez. 2005), editado por Carlos Eugênio de Carvalho Ferreira, que publicou três textos fundamentais para a discussão do bônus no Brasil: "Das causas às consequências econômicas da transição demográfica no Brasil” (PAIVA; WAJNMAN, 2005); "A demografia brasileira e o declínio da fecundidade no Brasil: contribuições, equívocos e silêncios" (CARVALHO; BRITO, 2005); e "Questões emergentes na análise demográfica: o caso brasileiro" (RIOS-NETO, 2005).

Outro marco no início da difusão do conceito foi a criação da lista de discussão População e Pobreza (grupo Yahoo), conhecida como P \& P, que buscou estimular o debate e manter um maior contato com os jornalistas. Nesse contexto, o membro da diretoria da Abep e moderador da lista P \& P (José Eustáquio Alves) postou uma mensagem, em 4 de janeiro de 2006, com o título do assunto "Bônus demográfico", incentivando o debate sobre o tema e publicando cinco textos na página da Abep. ${ }^{2}$ No mesmo dia, o demógrafo Cássio Turra respondeu a mensagem e divulgou um trabalho seu e de Bernardo Lanza (TURRA; QUEIROZ, 2005), além dos estudos do projeto "National Transfer Accounts". A discussão sobre o bônus continuou na lista P \& P e o jornalista Antônio Gois, que estava acompanhando a troca de mensagens, publicou no jornal Folha de S. Paulo (FSP) uma matéria de duas páginas, no domingo, dia 22 de janeiro de 2006, com o título "Bônus demográfico".

Dessa forma, o mês de janeiro de 2006 foi decisivo para a ampliação da discussão sobre o bônus demográfico na Abep e na sociedade brasileira. Em desdobramento, o ex-ministro e embaixador Rubens Ricupero publicou um artigo na Folha de S. Paulo, em 19/02/2006,

\footnotetext{
${ }^{1}$ Composição da diretoria 2005/2006: George Martine (presidente), Simone Wajnman (vice presidente), Rosana Baeninger (secretária geral), José Eustáquio Diniz Alves (tesoureiro) e José Ribeiro Soares Guimarães (suplente).

2 o cinco textos são: Martine, Carvalho e Arias (1994); Moreira (2001); Alves (2004); Rios-Neto (2005)e Wong e Carvalho (2005).
} 
comentando a matéria publicada por Antônio Gois, em que mostra uma surpresa pela falta de discussão sobre o tema e reconhece publicamente a importância do conceito de bônus demográfico. A partir destas iniciativas, o debate sobre bônus demográfico foi pautado, pela primeira vez na história da Abep, na programação do XV Encontro Nacional de Estudos Populacionais, ocorrido em Caxambu, de 18 a 22 de setembro de 2006. Nos anos seguintes, os principais veículos da imprensa brasileira publicaram editoriais divulgando a ideia do bônus demográfico e o conceito passou a fazer parte do dia a dia dos demógrafos, jornalistas e chegou aos formuladores de política econômica e social.

Mas, evidentemente, houve polêmicas no seio da Abep. Alguns demógrafos disseram não gostar do termo bônus, enquanto uns preferiam dividendo e outros "janela de oportunidade”. Os críticos dizem que a ideia de bônus demográfico tem um cunho neomalthusiano, pois pressupõe a queda da taxa de fecundidade, enquanto os defensores argumentam que a mudança da estrutura etária é uma decorrência da transição demográfica - ou seja, um fenômeno social da maior importância, que reflete conquistas civilizacionais como a queda das taxas de mortalidade e a regulação da fecundidade que, adotada de forma livre e consciente, também é uma conquista da capacidade de autodeterminação reprodutiva. Na prática, infelizmente, muitos críticos do bônus demográfico apenas reforçam as forças pronatalistas - de diferentes tipos - que adotam posturas antineomalthusianas, mas que, em última instância, ferem os direitos sexuais e reprodutivos.

Como mostraram Carvalho e Brito (2005), no final da década de 1970, nem os demógrafos admitiam que existia uma transição da fecundidade no país. 0 Brasil da época da ditadura e do início da redemocratização ainda repetia acriticamente a velha discussão sobre população e desenvolvimento, com um viés muito forte da crítica ao controlismo e ao neomalthusianismo, sem perceber que, progressivamente, o debate mundial já estava se deslocando para a sinergia existente entre uma estrutura etária favorável e os fundamentos da economia.

Mas, a despeito de toda polêmica, o Brasil, que nunca adotou nenhuma política oficial estabelecendo metas demográficas, viu as taxas de fecundidade caírem desde o final dos anos 1960 e, aos poucos, garantiu um aparato institucional favorável à liberdade nas decisões reprodutivas e uma legislação que assegurava as informações e os meios para o uso voluntário dos métodos contraceptivos. 0 § $7^{0}$ do artigo 226 da Constituição Federal, de 1988, define o planejamento familiar como um direito, o que foi regulamentado pela Lei n. 9.263 de 1996. Em 2007, o governo federal lançou a "Política Nacional de Planejamento Familiar", que tinha como meta a oferta de métodos contraceptivos de forma gratuita para homens e mulheres em idade reprodutiva, estabelecendo também a disponibilização da compra de anticoncepcionais na rede Farmácia Popular.

Em 2005, a taxa de fecundidade total no Brasil ficou, pela primeira vez, abaixo do nível de reposição. 0 povo brasileiro foi mais sábio do que os demógrafos antineomalthusianos e adotou a regulação da fecundidade, a despeito da insistência das forças pronatalistas. Com o bônus demográfico a pleno vapor, a economia brasileira iniciou um período de rápido 
crescimento do PIB, com geração de emprego e renda, redução da pobreza e diminuição, mesmo que tímida, das desigualdades sociais. O Brasil crescia, melhorava os indicadores de desenvolvimento humano e a população não era um problema. Ao contrário, passou a ser de reconhecimento amplo, geral e irrestrito que a baixa razão de dependência demográfica era uma das condições necessárias para o avanço do desenvolvimento brasileiro, ou para mitigar as consequências nefastas da crise, como mostrou Rios-Neto (2005) sobre os debates emergentes na demografia.

Mesmo com todas as resistências do conservadorismo moral, do fundamentalismo religioso e dos ideólogos desenvolvimentistas que defendem o crescimento populacional em nome da grandeza nacional, a ideia do bônus demográfico - enquanto o fenômeno temporário que acompanha a transição da estrutura etária - venceu e passou a fazer parte do vocabulário regular da mídia, dos acadêmicos de diversas áreas e das autoridades públicas. ${ }^{3}$

\section{O bônus demográfico brasileiro e ascensão e queda do mercado de trabalho}

O bônus demográfico começou no Brasil no primeiro quinquênio da década de 1970, quando teve início o processo de aumento da proporção da População em Idade Ativa sobre a população total (PIA/PT) e também houve um crescimento da proporção da população ocupada sobre a população total (PO/PT), que era de 31,7\% em 1970 e passou para $37,2 \%$ em 1980, segundo os dados dos censos demográficos. O Brasil aproveitou, mesmo que parcialmente, os frutos do dividendo demográfico (TURRA; QUEIROZ, 2005).

Mas, embora o bônus demográfico tenha começado no início da década de 1970 no Brasil, isso aconteceu sem que a sociedade brasileira discutisse ou agisse de forma consciente e deliberada para aproveitar as oportunidades geradas pela transição da estrutura etária. Entre 2004 e 2014, o Brasil viveu um dos melhores momentos do bônus demográfico, pois o PIB cresceu $50 \%$ e o PIB per capita aumentou $33 \%$, segundo dados do IBGE. Por conseguinte, houve grande geração de emprego formal e diminuição do grau de informalidade do mercado de trabalho.

Segundo dados do Cadastro Geral de Empregados e Desempregados (Caged), do Ministério do Trabalho, o estoque de emprego formal no Brasil era de 22,8 milhões de postos em novembro de 2002, chegou a 25,8 milhões em novembro de 2004 e apresentou um grande aumento durante a época do superciclo das commodities, alcançando a marca recorde de 41,3 milhões de postos de trabalho em novembro de 2014 . 0 aumento do emprego formal é um dos principais indicadores de que o Brasil estava aproveitando o bônus demográfico neste período.

De acordo com a Pesquisa Nacional por Amostra de Domicílios (PNAD anual), o percentual da população ocupada (PO) sobre a população total (PT) era de 45,5\% em 2002, passou

\footnotetext{
${ }^{3}$ Não há espaço aqui para relatar tudo que foi publicado, mas são inúmeros exemplos de matérias que foram repercutidas na televisão aberta e nos canais pagos, nos grandes jornais nacionais e regionais, nas principais revistas (Exame, Veja, Época, ISTOÉ, etc.) e outros canais da web tratando da questão dos desafios e das oportunidades do bônus demográfico.
} 
para 46,5\% em 2004 e chegou a 48,9\% em 2014, o maior valor da série que terminou em 2015 (com a descontinuidade da PNAD anual). Este aumento do nível de emprego total também mostrava que o país estava indo na direção certa de aproveitar o potencial da alta proporção de pessoas em idade ativa.

Decompondo os dados por sexo, observa-se que o percentual de homens ocupados sobre a população total foi de 26,7\% em 2002, 27,1\% em 2004 e 27,9\% em 2014, indicando que a proporção de homens inseridos no mercado de trabalho teve um leve aumento no período. Já o percentual de mulheres ocupadas sobre a população total passou de $18,8 \%$ em 2002 para 19,4\% em 2004 e alcançou 21,1\% em 2014.

Portanto, o aumento da força de trabalho ocorrido no período de maior crescimento da economia brasileira, no atual século, se deu em função da maior inserção feminina nas atividades produtivas, como já vinha acontecendo há décadas (BRUSCHINI, 1994; WAJNMAN, 2006). Houve, neste período, uma redução do hiato de gênero nas taxas de atividade e maiores ganhos de produtividade em função do fato de as mulheres possuírem níveis educacionais superiores aos dos homens. Por isso se diz que o bônus demográfico no Brasil é feminino.

Os dados da PNAD Contínua, que teve início em 2012, também mostram a mesma tendência de redução da desigualdade de gênero, pois o percentual da população ocupada (PO) sobre a população total (PT) permaneceu estável entre o segundo trimestre de 2012 e de 2014 , mas o percentual dos homens diminuiu de $27,7 \%$ para $27 \%$ e o das mulheres cresceu de $20,3 \%$ para $21 \%$, confirmando a tendência de maior inserção feminina nas atividades produtivas.

Contudo, o quadro promissor se inverteu com a maior e mais profunda recessão da história brasileira, que começou no 2ํㅡㄹ trimestre de 2014 e se aprofundou em 2015 e 2016. Este período, que foi seguido por uma retomada lenta nos três anos seguintes, gerou profundas perdas no mercado de trabalho e transformou a década de 2011 a 2020 em uma segunda década perdida e no período decenal com o pior desempenho do mercado de trabalho (BORÇA et al., 2019).

A literatura citada sobre o bônus demográfico mostra que não só o bom desempenho do mercado de trabalho é fundamental para o aproveitamento da janela de oportunidade demográfica, mas também um bom desempenho do sistema educacional. Há autores, inclusive, que consideram que o bônus demográfico depende fundamentalmente do avanço da educação (CUARESMA; LUTZ; SANDERSON, 2014). Mas, como mostrou Menezes-Filho (2001), apesar de ser fundamental para uma ampliação da força de trabalho, a educação brasileira também funciona como um mecanismo gerador de desigualdade de renda e outras desigualdades sociais.

Entretanto, o que ocorreu no último quinquênio no Brasil foi uma economia sem dinamismo e que não gera as oportunidades requeridas nem no mercado de trabalho nem na educação, especialmente para as mulheres que vinham avançando a passos mais rápidos do que os homens na inserção produtiva e educacional. Em dezembro de 2015, o Grupo de 
Trabalho Gênero da Abep e a Fundação Carlos Chagas organizaram o seminário "Até onde caminhou a revolução de gênero no Brasil? Implicações demográficas e questões sociais", ocorrido em São Paulo. Os principais trabalhos do evento foram publicados em livro com o mesmo título (ITABORAI; RICOLDI, 2016).

Na ocasião, explicitei uma visão - reconhecidamente pessimista - de que a crise econômica brasileira estava interrompendo seis décadas de aumento da taxa de ocupação das mulheres, reduzindo, inclusive, o percentual daquelas com curso superior nas atividades produtivas. A conjuntura econômica estava revertendo o processo de inserção feminina no mercado de trabalho exatamente no momento em que a estrutura etária brasileira encontrava-se em seu momento mais favorável, pois a razão de dependência demográfica apresentava os valores mais baixos no quinquênio 2015-20. Dessa forma, chamei a atenção para a tendência de "desempoderamento das mulheres brasileiras" e o desperdício do bônus demográfico feminino (ALVES, 2016).

No mesmo seminário, apresentando uma visão otimista, Wajnman (2016) entendia que a crise econômica teria, de fato, um efeito desastroso no curto prazo, mas, no longo prazo, os efeitos de composição provocados pela maior escolaridade feminina deveriam elevar novamente as taxas de atividade das mulheres na força de trabalho, possibilitando que as tendências de maior inserção feminina, de longo prazo, fossem retomadas e as desigualdades na taxa de participação entre homens e mulheres pudessem ser reduzidas.

0 que tentei argumentar nesse seminário da Abep/FCC foi que a crise econômica brasileira estava inviabilizando o aproveitamento da força de trabalho brasileira e provocando, artificialmente, o fim precoce do bônus demográfico, já que a baixa razão de dependência só se transforma, efetivamente, em ganhos econômicos e sociais se houver aproveitamento do potencial produtivo do capital humano.

Infelizmente, a realidade brasileira confirmou as previsões pessimistas e não as otimistas. Os dados do Cadastro Geral de Empregados e Desempregados (Caged) mostram que o estoque de emprego formal, que estava em 41,3 milhões de postos em novembro de 2014 , caiu nos anos seguintes e chegou a apenas 38,6 milhões de postos de trabalho em março de 2020. Uma perda de 2,7 milhões de empregos formais no período de quase seis anos. Ou seja, houve redução do emprego formal, enquanto a população total crescia.

Segundo os dados da PNAD Contínua, o percentual da população ocupada (PO) sobre a população total (PT) era de $45,3 \%$ no segundo trimestre de 2015 e diminuiu para $44,6 \%$ no segundo trimestre de 2019 . 0 percentual de homens ocupados sobre a população total, que correspondia a $25,8 \%$ no segundo trimestre de 2015 , reduziu-se para $24,6 \%$, enquanto o de mulheres ficou praticamente estável no período, passando de $19,5 \%$ para $19,7 \%$. Isso significa que, pela primeira vez, desde o fim da Segunda Guerra Mundial, o percentual feminino no mercado de trabalho não aumentou em uma década. Significa também que o melhor quinquênio da estrutura etária brasileira foi jogado fora pela crise econômica. 


\section{0 debate sobre o começo e o fim do bônus demográfico no Brasil}

O bônus demográfico é um fenômeno histórico e temporário, como mostraram Paiva e Wajnman (2005). Ele só acontece uma vez na história de qualquer país, pois é resultado da transição demográfica que, antes de tudo, é um acontecimento único, porque as taxas de mortalidade e natalidade, que sempre foram elevadas ao longo de milênios, começaram a cair no século XIX, chegaram a níveis mais baixos em todos os países do mundo no atual século e, fora algumas oscilações conjunturais, não se imagina a volta aos padrões anteriores ao período pré-transicional. 0 bônus acontece no momento intermediário da passagem de uma estrutura etária rejuvenescida para uma estrutura envelhecida. Mas quando começa e quando termina o bônus demográfico?

O bônus começa quando a maior proporção de pessoas em idade ativa se transforma em taxas mais elevadas de participação efetiva de indivíduos no mercado de trabalho, de preferência de pessoas com maiores níveis educacionais e melhores condições de saúde. Nos últimos 15 anos, os demógrafos brasileiros publicaram muitos estudos de alta qualidade sobre os desafios e as oportunidades da janela de oportunidade (WONG; CARVALHO, 2005; QUEIROZ; TURRA, 2010; RENTERÍA et al., 2016; BAERLOCHER; PARENTE; RIOS-NETO, 2019).

Sem ter a pretensão de uma análise mais elaborada, como nos textos citados e na vasta literatura que tem sido publicada, podemos dizer, de modo simples, que o bônus acontece quando a proporção de trabalhadores efetivos (proporção de pessoas que geram renda do trabalho) cresce mais rápido do que a proporção de consumidores efetivos (TURRA, 2018). A forma mais simples de medir o bônus é por meio da porcentagem da população ocupada (trabalhadores efetivos) em relação à população total (consumidores totais efetivos).

Mas existe uma forma ainda mais fácil de se medir o bônus, que é quando a PIA cresce mais rapidamente do que a população total (PT). Nesse caso, o bônus começa quando a proporção PIA/PT aumenta e acaba quando diminui. 0 problema dessa fórmula simples é que a proporção PIA/PT pode estar crescendo e o emprego efetivo (população ocupada PO) não acompanhar (devido ao alto desemprego e à subutilização da força de trabalho), criando uma situação de uma estrutura etária mais favorável ao desenvolvimento econômico, mas que está sendo desperdiçada por falta de políticas e investimentos de geração de emprego. Da mesma maneira, a proporção PIA/PT pode estar diminuindo, mas o emprego efetivo pode estar crescendo em decorrência de um aumento da população ocupada e de inserção de novos grupos populacionais que estavam fora do mercado de trabalho (jovens, mulheres, idosos, etc.).

Portanto, o melhor indicador para medir o começo e o fim do bônus demográfico é a proporção PO/PT: se ela cresce, há o aproveitamento do bônus; se diminui, tem-se o desperdício do bônus. 0 uso da fórmula mais simples está por detrás de uma polêmica recente sobre o fim do bônus demográfico no Brasil e que tomou corpo quando o IBGE divulgou as novas projeções populacionais (revisão 2018), em julho de 2018. 
Repercutindo o material divulgado pelo IBGE, o jornalista Bruno Villas Boas, do jornal Valor, publicou uma matéria com o título "Bônus demográfico termina com menor alta da população ativa" (VILLAS BOAS, 2018). Na reportagem, o economista Samuel Pessoa, do Instituto Brasileiro de Economia da Fundação Getúlio Vargas (Ibre/FGV), disse: “É verdade que o bônus demográfico termina em 2018, quando é considerado que o crescimento da população em idade ativa é menor do que o crescimento da população total”. Na mesma reportagem, apresentei uma outra visão: "A janela demográfica começou a se fechar, mas não fechou ainda totalmente. Vai entrar menos luz na economia. A questão é que ela não está sendo aproveitada com o atual nível de desemprego".

Ou seja, esta reportagem, ocorrida a partir da divulgação das novas projeções populacionais do IBGE, reflete duas maneiras de se ver o fim do bônus demográfico: uma considera que o bônus brasileiro já acabou, pois a proporção PIA/PT começou a diminuir; e a outra entende que o bônus pode continuar contribuindo para o processo de desenvolvimento brasileiro enquanto a proporção PO/PT continuar a aumentar. Isso quer dizer que, do ponto de vista da demografia, a janela de oportunidade só vai se fechar totalmente quando a PIA começar a diminuir não em termos relativos, mas sim em termos absolutos. No período em que a PIA estará crescendo em números absolutos é possível aumentar o percentual da população ocupada se a macroeconomia for capaz de gerar os empregos suficientes.

Um exercício simples pode esclarecer esta questão. Segundo o Censo Demográfico 2010, a PIA brasileira representava $66,3 \%$ da população total (PT) e a população ocupada (PO) correspondia a $45,3 \%$ da PT naquele ano. Segundo as projeções do IBGE (revisão 2018), a PIA vai crescer em termos absolutos até 2037 , quando será $66,3 \%$ da população total do país. Se o percentual da PO (que chegou ao máximo em $46 \%$ em 2014) crescer até $50 \%$ até 2037 , haveria um aproveitamento do bônus demográfico, pois o número de trabalhadores efetivos (PO) estaria aumentando em relação aos consumidores efetivos (PT). Assim, a janela de oportunidade demográfica poderia ser aproveitada até 2037, quando o processo de envelhecimento populacional provocaria a redução absoluta da PIA.

Dizer que o bônus brasileiro já acabou (do ponto de vista demográfico) é o mesmo que considerar que o processo de envelhecimento já representa um ônus para o país. Foi exatamente esta a conclusão exposta em uma reportagem do jornal Folh a de S. Paulo que, em manchete estampada com destaque na edição de 9 de fevereiro de 2020, disse que 0 "Envelhecimento do Brasil já compromete o crescimento" e o país "já vive um ônus demográfico" (CUCOLO, 2020). A matéria foi elaborada com base em um estudo do lbre/FGV.

Em resposta escrevi um artigo no Portal do Envelhecimento, argumentando que responsabilizar a demografia pelo fim do bônus é um equívoco:

O Brasil ainda pode dar o salto para o clube de países com alto Índice de Desenvolvimento Humano (IDH). Mas para tanto, não se pode culpar o envelhecimento atual e antecipar a etapa do ônus demográfico (como fez a FSP) e sim buscar políticas universais de emprego e educação para dar vez ao potencial produtivo do país. Os próximos 20 anos serão decisivos para o futuro do Brasil. (ALVES, 2020) 


\section{0 golpe mortal da Covid-19 sobre o bônus demográfico brasileiro}

0 réveillon de 2020 começou, como sempre, com muitas festas, fogos de artifícios e votos de feliz ano novo. Porém, ninguém poderia imaginar que o primeiro semestre do ano seria marcado por uma pandemia só equivalente à da gripe espanhola de 102 anos atrás. 0 impacto econômico tem sido monstruoso e ainda terá que ser mais bem avaliado no futuro. No início do ano, o mundo tomou conhecimento de uma nova doença que surgiu na China, provocada por um novo tipo de coronavírus e ninguém imaginava a dimensão do problema que estava por vir. Em janeiro, uma equipe de médicos chineses foi encarregada de investigar o início de uma doença conhecida como "pneumonia de Wuhan". Em 24 de janeiro foi publicado um relatório na revista The Lancet, identificando um primeiro paciente que apresentou sintomas no último mês do ano anterior. A doença foi batizada de Covid, que significa corona virus disease (doença do coronavírus). Como os primeiros casos aconteceram em 2019, então a doença ficou Covid-19.

Em pouco mais de seis meses a pandemia do Sars-CoV-2 registrava, até 20 de julho, 15 milhões de pessoas infectadas e 610 mil mortes, globalmente. No Brasil, no mesmo dia, eram contabilizados mais de 2,1 milhões de casos e 80 mil óbitos. Isso tudo sem contar as subnotificações. Indubitavelmente, o mundo vive uma enorme emergência sanitária. Vive também uma contração econômica sem paralelo na história. Segundo o Fundo Monetário Internacional (FMI), o resultado da paralisação das atividades econômicas, em decorrência das medidas de isolamento social para evitar a propagação da pandemia da Covid-19, deve provocar uma queda de 4,9\% no Produto Interno Bruto (PIB) no mundo e 9,1\% no Brasil. Não houve um ano assim, nem na crise da década de 1930 (IMF, 2020).

Estudo da Comissão Econômica para a América Latina e o Caribe (CEPAL, 2020) mostra que a pandemia da Covid-19 atingiu a América Latina e o Caribe (ALC) em um momento de debilidade macroeconômica, pois, no decênio posterior à crise financeira de 2008/09, 0 continente apresentou em média o menor crescimento desde a década de 1950. A Cepal estima um aumento do desemprego e da pobreza e uma redução da renda per capita de todos os países da região, com uma queda do PIB, em 2020, de 5,3\% na ALC e de 5,2\% no Brasil. Evidentemente, quanto maior for o impacto da pandemia maior será o pandemônio econômico e maior será o sofrimento das populações afetadas. Evidentemente, toda esta crise vem em péssima hora. A produtividade no Brasil está estagnada há mais de 30 anos e a economia só crescia, mesmo que em ritmo lento, devido ao incremento da taxa de atividade da força de trabalho (NEGRI; CAVALCANTE, 2014).

Mas existe uma outra tragédia pouco evidenciada, que está acontecendo com a população jovem, vítima da emergência econômica e social. Os pesquisadores Major e Machin (2020), da London School of Economics, estão preocupados com a chamada "geração Covid", que são os jovens com menos de 25 anos que estão ameaçados de viverem um processo de mobilidade social descendente. Esta geração pode ser obrigada a fazer a transição para a vida adulta numa sociedade com aumento das desigualdades econômicas 
e educacionais. Os autores consideram que, antes da pandemia, as gerações mais jovens já enfrentavam redução da mobilidade absoluta: salários reais em queda; menos oportunidades; padrões de vida estagnados e até em declínio; e crescente espectro de retrocesso nas condições de vida. 0 grande perigo agora é que a Covid-19 possa mergulhar os jovens em uma idade sombria de declínio da mobilidade social.

Enquanto a maioria da população idosa brasileira está coberta pelo sistema de aposentadoria, pensão ou proteção social (como o Benefício de Prestação Continuada - BPC), a "geração Covid" está completamente desprotegida. Pior, os jovens brasileiros estão sendo os mais afetados pela deterioração do mercado de trabalho pós-pandemia do novo coronavírus. No primeiro trimestre deste ano, 41,8\% da população de 18 a 24 anos estava na categoria que o IBGE chama de subutilizados - ou estavam desempregados, ou desistiram de procurar emprego ou tinham disponibilidade para trabalhar por mais horas na semana. Também, é preciso ressaltar que, mesmo no período áureo do mercado de trabalho, existiam mais de 10 milhões de jovens classificados como "nem-nem" e que estavam fora da escola e do mercado de trabalho, portanto, fora da possibilidade de serem aproveitados pelo bônus demográfico.

Vale lembrar que a avaliação sobre o fim do bônus pode ocorrer pelo foco na dinâmica demográfica (crescimento relativo da PIA) ou pelo foco na dinâmica econômica (crescimento relativo da PO). Mas, em qualquer perspectiva, o bom desempenho do mercado de trabaIho é essencial. Nesse sentido, o bônus demográfico no Brasil já estava sendo totalmente desperdiçado desde 2015, quando as taxas de atividade começaram a cair após a recessão econômica que começou no segundo trimestre de 2014 e se aprofundou em 2015 e 2016. A lenta recuperação do período 2017 a 2019 não foi capaz de aumentar a proporção de pessoas ocupadas no conjunto da população. Assim, o melhor quinquênio da história da estrutura etária brasileira, o período 2015-20, quando a razão de dependência demográfica estava em seus menores valores e a proporção PIA/PT ainda era crescente, foi desperdiçado pela conjugação de uma crise econômica, social e política.

A esperança seria que houvesse uma recuperação no mercado de trabalho em $2020 \mathrm{e}$ nos anos seguintes. Contudo, a pandemia do novo coronavírus mudou tudo. No mundo, já são mais de 16 milhões de pessoas infectadas e cerca de 645 mil mortes até 24 de julho. No Brasil, a pandemia do Sars-CoV-2 já atingiu mais de 2,3 milhões de pessoas e matou mais de 85 mil. Em decorrência, diversas instituições internacionais que fazem projeções econômicas, como o Banco Mundial, o Fundo Monetário Internacional e a Comissão Econômica para a América Latina e o Caribe (Cepal), consideram que a crise econômica de 2020 será a mais profunda da história mundial e também da América Latina e do Brasil. Evidentemente, o impacto no mercado de trabalho será ainda maior do que aquele provocado pela crise de 2014 a 2016.

De fato, os dados do Caged e da PNAD Contínua já mostravam uma deterioração em fevereiro e março de 2020, antes do agravamento da pandemia da Covid-19. Mas a avaliação mais recente e preocupante veio com a divulgação da pesquisa PNAD COVID19 (IBGE, 2020), 
que estimou apenas 84,4 milhões de pessoas ocupadas no país, em maio, o que significa que, pela primeira vez, o Brasil tem menos da metade da PIA de 169,9 milhões de pessoas trabalhando, pois houve aumento do desemprego e da população fora da força de trabalho.

Os números trazidos pela pesquisa PNAD COVID19 do IBGE mostram que o Brasil não vive apenas uma emergência sanitária, mas também uma emergência econômica e social. Pela primeira vez na história, a população ocupada (PO) representa menos da metade das pessoas em idade de trabalhar (PIA). E o mais grave, a população ocupada representa apenas $40 \%$ da população total (PT), conforme mostra a Tabela 1.

TABELA 1

População total e população fora e dentro da força de trabalho Brasil - maio 2020

\begin{tabular}{lc}
\hline População & 24 a 30/05 de 2020 (em mil) \\
\hline População total (PT) & 210.927 \\
Pessoas de 14 anos e mais (PIA) & 169.907 \\
Pessoas de 14 anos e mais na força de trabalho & 95.307 \\
Pessoas de 14 anos e mais ocupadas (PO) & 84.431 \\
Pessoas de 14 anos e mais desocupadas & 10.875 \\
Pessoas de 14 anos e mais fora da força de trabalho & 74.600 \\
População total não empregada & 126.496 \\
\hline PO/PIA (\%) & 49,7 \\
\hline PO/PT (\%) & 40,0 \\
\hline
\end{tabular}

Fonte: IBGE. PNAD COVID19, 16 de junho de 2020.

Ou seja, $60 \%$ da população brasileira, um contingente de 126,5 milhões de pessoas, não está ocupada. Isso é um desperdício colossal do potencial produtivo do país. Para se ter uma comparação internacional, os números da China e do Vietnã indicavam $60 \%$ da população total inserida em atividades produtivas (atualmente variam entre 55\% e 57\%). Portanto, o Brasil poderia ter cerca de 40 milhões a mais de trabalhadores gerando riqueza, em vez de estarem na "rua da amargura".

Uma crise dessa dimensão, obviamente, atinge de maneira dramática o emprego feminino e a PNAD Contínua indica que 7 milhões de mulheres foram expulsas do mercado de trabalho desde março de 2020. Assim, os ganhos na maior igualdade de gênero nas taxas de atividade, que vinham ocorrendo por mais de 60 anos, estão comprometidos na atualidade. Ao invés de manter a tendência de redução das desigualdades de gênero no mercado de trabalho, a saída de grande contingente de mulheres do mercado de trabalho pode reforçar o processo de "desempoderamento feminino".

0 artigo 23 da Declaração Universal dos Direitos Humanos, da ONU, de 10/12/1948, diz: "Todo ser humano tem direito ao trabalho, à livre escolha de emprego, a condições justas e favoráveis de trabalho e à proteção contra o desemprego". 0 artigo 6으 da Constituição Federal, de 1988, afirma que o trabalho é um direito fundamental de todo cidadão brasileiro.

Mas, além de ser um direito, o trabalho também é uma necessidade para o progresso do país. Não é necessário fazer referência à teoria do valor de Marx, pois alguém 
poderia dizer que se trata de uma visão própria do "marxismo cultural”. Basta lembrar o que foi dito no consagrado livro A riqueza das nações, publicado em 1776, por Adam Smith (1723-1790): “O trabalho anual de cada nação constitui o fundo que originalmente the fornece todos os bens necessários e os confortos materiais que consome anualmente" (SMITH, 1983, p. 35). Ou seja, a riqueza das nações depende do trabalho produtivo e não existe nação rica e desenvolvida sem que tenha havido o aproveitamento efetivo da sua força de trabalho total.

Do ponto de vista macroeconômico, a crise do mercado de trabalho vem na pior hora, pois o Brasil apresentou no quinquênio 2015-20 a menor razão de dependência demográfica da sua história. Isto é, a maior proporção de pessoas em idade ativa. Maior proporção em relação não só à história passada, quando havia uma alta presença de crianças e adolescentes, mas também à história futura, quando haverá cada vez mais idosos como porcentagem do conjunto da população. A crise no mercado de trabalho brasileiro não é de agora, vem desde 2015. Mas, sem dúvida, a emergência sanitária agravou a situação. Uma população doente, sem trabalho e com as atividades econômicas paralisadas, mesmo que parcialmente, forma um quadro dramático.

\section{Futuro do bônus demográfico: a morte precoce}

Como vimos, o afloramento do debate sobre o bônus demográfico, no início dos anos 2000 no Brasil, começou com muito atraso e quando a "criança”, de fato, já era um "adulto". Mesmo assim, antes tarde do que nunca. Embora sempre tenha havido incompreensões e resistências ao conceito, o termo veio para ficar e já faz parte do vocabulário corrente. Uma consulta ao Google indica que a expressão "bônus demográfico" possui 580 mil referências em português e 15 milhões em inglês.

Já a discussão sobre o fim do primeiro bônus demográfico no país estava apenas começando e, assim mesmo, estava meio obnubilada pela crise econômica e política que vem polarizando o país desde 2014 (sem o aproveitamento do primeiro bônus demográfico fica difícil capitalizar o segundo). 0 Brasil está finalizando a segunda década perdida, com estagnação dos indicadores de desenvolvimento. Para evitar a possibilidade de uma terceira década perdida, seria necessário discutir os instrumentos de política macroeconômica necessários para impulsionar o mercado de trabalho e os níveis de produtividade da economia, para aproveitar os momentos finais do bônus demográfico, quando a janela de oportunidade começa a se fechar, mas ainda não se fechou de todo.

Com esforço, seria possível colher os últimos frutos da estrutura etária favorável. Todavia, a crise sanitária passou a atrair todas as atenções e as políticas macroeconômicas passaram a dar prioridade ao novo cenário de emergência na saúde e na economia. 0 curto prazo tende a ocupar todas as atenções e a discussão sobre o fim do bônus demográfico, de certa forma, parece ter uma morte precoce, assim como o debate sobre um projeto de longo prazo para o futuro do país. 
Indubitavelmente, quanto maiores forem os números da pandemia da Covid-19, menores serão os número da criação de postos de trabalho. 0 Brasil já é o segundo país mais impactado pela pandemia (atrás apenas dos EUA), mas está em primeiro lugar no número de casos e mortes diárias e nem chegou ao zênite da curva. Os exemplos internacionais mostram que a curva epidemiológica tem um forma normal assimétrica, pois o lado direito é duas ou três vezes maior do que o lado esquerdo. Isso quer dizer que, em nível nacional, o número de casos e de mortes pelo novo coronavírus deve ser maior no segundo do que no primeiro semestre.

O Brasil também será um dos países mais impactos na economia, pois terá o maior déficit fiscal de sua história e um grande aumento da dívida pública. 0 relatório do FMI estima que o déficit nominal será de $16 \%$ do PIB e a dívida pública deve chegar a $102 \%$ do PIB em 2020 (IMF, 24/06/2020). A economia brasileira já estava enfraquecida antes da emergência sanitária, com baixa produtividade dos fatores de produção, baixa competitividade internacional, baixo dinamismo na produção de bens e serviços, baixa geração de emprego decente, baixa geração de renda, baixo investimento e com piora nos indicadores de pobreza e desigualdade social.

Há muitas fragilidades macroeconômicas e a carência de emprego é um verdadeiro calcanhar de Aquiles. Sem uma alta inserção laboral nenhuma nação tem futuro, pois o trabalho é a fonte de toda a riqueza. No meio de tanta barafunda macroeconômica, ter mais da metade da população em idade ativa fora do mercado de trabalho é o mesmo que enterrar as chances de sobrevida da janela de oportunidade. 0 debate sobre o fim do bônus demográfico parece que está indo para a vala comum.

Dessa forma, a pandemia da Covid-19 poderá ser a pá de cal no sonho de se aproveitar o restante do bônus demográfico, em meio às desfavoráveis condições atuais da economia brasileira. Está cada vez mais distante a possibilidade de implementação das bandeiras do "pleno emprego e trabalho decente" e da educação de qualidade para todos, tão necessárias para efetivar a meta do fim da pobreza e o objetivo da plena equidade social, inclusive para cumprir a Agenda 2030 da ONU. A chamada "geração Covid" deve pagar um alto preço em decorrência da piora das condições de emprego e educação.

Se a conjuntura negativa que já prevalece desde 2014 não for revertida, as atuais adversidades poderão ser o enterro da ideia fundamental da emancipação via trabalho e do direito à autodeterminação produtiva. Perder a oportunidade histórica de aproveitar uma estrutura etária favorável poderá ser a perda do sonho de uma nação próspera, justa e feliz. 


\section{Referências}

ALVES, J. E. D. A polêmica Malthus versus Condorcet reavaliada à luz da transição demográfica. Rio de Janeiro: Escola Nacional de Ciências Estatísticas, 2002. (Textos para Discussão, v.4).

ALVES, J. E. D. O bônus demográfico e o crescimento econômico no Brasil. Aparte, IE/UFRJ, 2004. ALVES, J. E. D. População, bem-estar e tecnologia: debate histórico e perspectivas. Multiciência, v. 6, p. 1-22, 2006.

ALVES, J. E. D. Crise no mercado de trabalho, bônus demográfico e desempoderamento feminino. In: ITABORAI, N. R.; RICOLDI, A. M. (org.). Até onde caminhou a revolução de gênero no Brasil? Belo Horizonte: Abep, 2016. p. 21-44. ISBN 978-85-85543-31-0.

ALVES, J. E. D. O envelhecimento já compromete o crescimento econômico no Brasil? Portal do Envelhecimento, São Paulo, 10/02/2020.

BAERLOCHER, D.; PARENTE, S. L.; RIOS-NETO, E. Economic effects of demographic dividend in Brazilian regions. The Journal of the Economics of Ageing, v. 14, 100198, 2019.

BARROS, R. P.; FIRPO, S.; BARRETO, R. G.; LEITE, P. G. P. Demographic changes and poverty in Brazil. In: BIRDSALL, N.; KELLEY, A. C.; SINDING, S. W. (ed.). Population matters: demographic change, economic growth, and poverty in the developing world. Oxford: Oxford University Press, 2001.

BIRDSALL, N.; KELLEY, A. C.; SINDING, S. W. (ed.). Population matters: demographic change, economic growth, and poverty in the developing world. Oxford: Oxford University Press, 2001.

BLOOM, D. E.; WILLIAMSON J. G. Demographic transitions and economic miracles in emerging Asia. World Bank Economic Review, v. 12, n. 3, p. 419-56, 1998.

BORÇA JR., G.; BARBOZA, R. M.; FURTADO, M. A recuperação do PIB brasileiro em recessões: uma visão comparativa. Blog do Ibre, 02/05/2019.

BRUSCHINI, C. O trabalho da mulher brasileira nas décadas recentes. Revista Estudos Feministas, ano 2, número especial, p. 179-199, 1994.

CARVALHO, J. A. M. Para onde iremos: algumas tendências populacionais no século XXI. Revista Brasileira de Estudos de População, v. 18, n. 1/2, 2001.

CARVALHO, J. A. M.; BRITO, F. A demografia brasileira e o declínio da fecundidade no Brasil: contribuições, equívocos e silêncios. Revista Brasileira de Estudos de População, v. 22, n. 2, jul./dez. 2005.

CEPAL - Comissão Econômica para a América Latina e o Caribe. Dimensionar los efectos del COVID-19 para pensar en la reactivación. Informe Especial, n. 2, 21/04/2020.

COALE, A.; HOOVER, E. População e desenvolvimento econômico. Rio de Janeiro: Fundo de Cultura, 1966.

CUARESMA, J. C.; LUTZ, W.; SANDERSON, W. Is the demographic dividend an education dividend? Demography, v. 51, n. 1, p. 299-315, 2014.

CUCOLO, E. Envelhecimento do Brasil já compromete o crescimento. Folha de S. Paulo, 9 fev. 2020.

CUTLER, D. M.; POTERBA, J. M.; SHEINER, L. M.; SUMMERS, L. H.; AKERLOF, G. A. An aging society: opportunity or challenge? Brookings Papers on Economic Activity, v. 21, n. 1, p. 1-73, 1990.

GOIS, A. Bonus demográfico: Brasil desperdiça “ajuda” da demografia. Folha de S. Paulo, caderno Mercado, 22 jan. 2006. 
IBGE - Instituto Brasileiro de Geografia e Estatística. Pandemia dificulta acesso de 28,6 milhões de pessoas ao mercado de trabalho em maio. Agência IBGE Notícias, 16/06/2020.

IMF - International Monetary Fund. A crisis like no other, an uncertain recovery. World Economic Outlook Update, 24/06/2020.

ITABORAI, N. R.; RICOLDI, A. M. (org.). Até onde caminhou a revolução de gênero no Brasil? Belo Horizonte: Abep, 2016.

LEE, R. MASON, A.; MILLER, T. Life cycle saving and the demographic transition: the case of Taiwan. Population and Development Review, v. 26, supplement: Population and Economic Change in East Asia, p. 194-219, 2000.

MAJOR, L. E.; MACHIN, S. Covid-19 and social mobility. London: Centre for Economic Performance, London School of Economics, May 2020. (A CEP Covid-19 analysis, n. 4).

MARTINE, G.; CARVALHO, J. A. M.; ARIAS, A. R. Mudanças recentes no padrão demográfico brasileiro e implicações para a agenda social. Rio de Janeiro: Ipea, 1994. (Texto para Discussão, n. 345).

MENEZES-FILHO, N. A. A evolução da educação no Brasil e seu impacto no mercado de trabalho. Instituto Futuro Brasil, 2001.

MOREIRA, M. M. Structural changes in the Brazilian age distribuition: 1950-2050. In: XXIV IUSSP INTERNATIONAL POPULATION CONFERENCE. Proceedings [...]. Salvador: IUSSP, 2001.

NEGRI, F.; CAVALCANTE, L. R. (org.). Produtividade no Brasil: desempenho e determinantes. Brasília: ABDI, Ipea, 2014.

PAIVA, P. T.; WAJNMAN, S. Das causas às consequências econômicas da transição demográfica no Brasil. Revista Brasileira de Estudos de População, v. 22, n. 2, p. 303-322, jul./dez. 2005.

QUEIROZ, B. L.; TURRA, C. M. Window of opportunity: socioeconomic consequences of demographic changes in Brazil. Washington, DC: NTA, 2010.

RENTERÍA, E.; SOUTO, G.; MEJÍA-GUEVARA, I.; PATXOT, C. The effect of education on the demographic dividend. Population and Development Review, v. 42, n. 4, p. 651-671, 2016.

RICUPERO, R. Opinião econômica: o que há de novo? Folha de S. Paulo, caderno Mercado, 19 fev. 2006.

RIOS-NETO, E. L. G. Questões emergentes na análise demográfica: o caso brasileiro. Revista Brasileira de Estudos de População, v. 22, n. 2, p. 371-408, jul./dez. 2005.

SMITH, A. A riqueza das nações. São Paulo: Abril Cultural, 1983.

TURRA, C. Os ajustes inevitáveis da transição demográfica no Brasil. In: VIEGAS, M.; ALBUQUERQUE, E. M. Alternativas para uma crise de múltiplas dimensões. Belo Horizonte: Cedeplar/UFMG, 2018.

TURRA, C. M.; QUEIROZ, B. L. Before it's too late: demographic transition, labour supply and social security problems in Brazil. In: UNITED NATIONS EXPERT GROUP MEETING ON SOCIAL AND ECONOMIC IMPLICATIONS OF CHANGING POPULATION AGE STRUCTURES. Proceedings [...]. México: Departamento de Assuntos Econômicos e Sociais, Divisão de População, 2005.

VILLAS BOAS, B. Bônus demográfico termina com menor alta da população ativa. Valor, 26/07/2018.

WAJNMAN, S. "Quantidade" e "qualidade" da participação das mulheres na força de trabalho brasileira. In: ITABORAI, N. R.; RICOLDI, A. M. (org.). Até onde caminhou a revolução de gênero no Brasil? Belo Horizonte: Abep, 2016. p. 45-58. 
WAJNMAN, S. Mulheres na sociedade e no mercado de trabalho brasileiro: avanços e entraves. In: PORTO, M. (org.). Olhares femininos, mulheres brasileiras. Rio de Janeiro: X Brasil, 2006. p. 77-108.

WONG, L.; R.; CARVALHO, J. A. M. Demographic bonuses and challenges of the age structural transition in Brazil. In: XXV IUSSP INTERNATIONAL POPULATION CONFERENCE. Proceedings [...]. Tours, France: IUSSP, 18-23 July 2005.

WORLD BANK. The East Asian miracle; economic growth and public policy. World Bank, 1993.

\section{Sobre 0 autor}

José Eustáquio Diniz Alves é doutor em Demografia pelo Centro de Desenvolvimento e Planejamento Regional (Cedeplar) da Universidade Federal de Minas Gerais (UFMG), com pós-doutorado no Núcleo de Estudos de População (Nepo), da Universidade Estadual de Campinas (Unicamp). Pesquisador aposentado.

\section{Endereço para correspondência}

Praia do Flamengo, 98, ap. 209, Flamengo

22210-030 - Rio de Janeiro-RJ, Brasil

Recebido para publicação em 20/06/2020

Aceito para publicação em 21/07/2020 